\title{
Effectiveness of Charcoal Drawing Packages on Academic Achievement of Fine and Applied Arts Students of Nigeria University
}

\author{
Michael Olubunmi Odewumi, Bamidele Stephen Omoyajowo \\ Amos Ochayi Onojah, Iyabo Romoke Ajala \\ Department of Educational Technology, Faculty of Education \\ University of Ilorin. Ilorin. Nigeria
}

\begin{abstract}
Drawing is a compulsory course of study which are manifested in all other fine art courses in Nigeria University, the study was motivated by the yearly recorded mass failure that make it imperative for drawing lecturers to vary both the method and media in drawing instruction. Therefore, the study investigated the effectiveness of charcoal drawing packages on academic achievement of fine and applied arts students of Nigeria University. The quasi experimental post-test group design was used for the study. Sixty (60) part two students comprised (thirty-two males and twenty-eight females) of the department of fine and applied art were randomly selected to represent the sample for the study. The students were randomly assigned to the experimental and control groups respectively. The students in the experimental group were taught using Charcoal Drawing Packages (CDP) while the control group was taught using conventional method. The treatment for the study was the Charcoal Drawing Packages (CDP) and the main instrument used was Test Instrument Fine and Applied Arts Test (TIFAA) the instrument was subjected to content and face validation. A 100-items Test Instrument in Fine and Applied Arts (TIFAA) was administered to the students as post-test after the treatment. Two hypotheses were postulated and tested at 0.05 level of significance using t-test. The analysis revealed that there was a significant difference between the scores of students taught with the Charcoal Drawing Packages (CDP). Based on these findings, it is recommended that the Charcoal Drawing Packages (CDP) should be encouraged to be used for instructional purposes in the University for teaching related concepts in fine and applied art.
\end{abstract}

\section{Introduction}

The word Arts lies in the formative knowledge of younger ones [22]. It is acknowledged as the totality of a man's originality in creative world [41]. Although, Art is the pronouncement of one's feelings, ideas, thoughts and mental pictures in diverse link. It is also described as a way in which things appeal to the eyes and minds of people which is the state of mind [51]. Arts is therefore divided into Non-Visual and Visual. The non-visual are referred to as performing and liberal arts. The end means of performing arts are music, drama, dance etc. Whereas, the liberal arts consist of writing and poetry. Visual art is divided into Fine and Applied arts, which are taught in Nigerian University, with specialised courses on Drawing, Painting, Sculpture, Architect, Textile, Photography, Music, Crafts and Graphics, with emphasises on drawing as the foundation for all.

Fine and Applied arts are concerned with thoughts and making of valuable visuals through ideas using different media and methods for producing objects of artistic values such as painting, sculpture, drawing and crafts. Applied arts are otherwise grouped as industrial arts this involves designing, inventing and producing of artistic objects of beautification and utilitarian. Ceramics, textile design, photography, architecture, computer graphic design, fashion design, interior design, as well as all decorative arts are included in this category of applied arts. The study of Adams [1] established that Fine and Applied Arts Education as a development of learning that enables individual to survive as a useful and acceptable member of the social order. It is a way of eradicating poverty, selfreliance and a suitable factor for socio-economic liberation of the country.

The Federal Government (FGN) in the National Policy on Education (NPE, 2009) defined Fine and Applied Arts Education as the instruction that gives its beneficiary vision to obtain practical talents as well as some basic scientific knowledge. Hall [19] has submitted that art education gives the groundwork for future opportunity in training of individuals.

Arts Education is a vital component of national development scheme in many nations because of its great influence on productivity and economic expansion and it is geared towards the training of the skilled person who can in actual fact work with his head, heart and hands. The study of Bartel [3] further expatiated two principal objectives of art education as developing an individual to the height of his gifts and adding to the social-economic stability of the populace. Arts education accommodates utilised indigenous and contemporary method for skill acquisition and competence. Nevertheless, the integration of arts education fosters 
and develops researchers for its consolidative merits. It also ushered in valuable hints that developing cognition, creativity, social interactions, and motor control of individual (Bowman, Donovan and Burns, 2001).

\section{Meaning of drawing}

Review of empirical studies on the meaning of drawing, revealed, among others, that Drawing is a form of diverse mark through making with different media that tends to satisfy people for different representation [21]. The study of Szántó [46] explained that drawing is a language through which learners use a variety of artistic media as a means of expressions for the visual interpretations. Okorie [34] expressed that drawing is a globally accepted as graphical expression of language via different lines for sciences.

Drawing is also most common language medium of expression by all and sundry without correction and mostly features with the technicians, engineers, designers, craftsmen, manufacturers. Keefe et al. [25] has argued that conformist style of drawings brings wobbly and gesture, which stabilises the hand and easily scribbled. Rubin [39] described drawings as the universal medium of expression of infancy. Hawkins [19] expatiated further that the infancy expression are in three stages as cognitive, affective and linguistic. Pérez-Gómez and Pelletier [36] reaffirmed that it has a great effect on the ability of learners to converse and develop through different artist medium and style.

In essence, from the regeneration and the advancement, drawing became a new activity in the creation process of arts. Drawing consists of notation and geometry sketches from engineers, architects, electricians, interior designers and technical drafters [15]. Drawings are prominent and have a link with other subjects in the school curriculum. It also identified as a very important and has a root in scientific and technological development of any nation [2]

The study of Sobel [45] revealed that maps and drawings are illustrations of things that are sensitively and cognitively important to students in learning social studies. Tuman [51] disclosed that perfect lines of drawing also indicate importance of mapping in geography where higher intensity strokes of lines shows more attention and detailed emphasises. Okanlawon [33]) submitted that the various lines are otherwise referred to as strokes in drawings. Hecker and Kentridge [20] concluded that constant expression of hand and brain associations enabled drawing to be seen as a perfect way of acquiring new knowledge, centre activity in proficient skill of producing landscape and architecture.
Hope [21] stressed that drawing is imperative, it is of immense and accessible instrument that allows students to learn and comprehend the ideas and concept of other people in way of successfully develop, generate, expand, and communicate of their own ideas. Anning and Ring [5] submitted that (p. 54) drawing develops, creates and communicates to learners' opinion, perception and inspiration. Taylor et al. [47] explained that drawing serves as a means of passing message and process of assembly facts through lines on paper. Similarly, Hopperstad [22] submitted that drawings gives meaning and helps learners to coherent ideas and though in different ways. Drawing are used to express their opinion more clearly than using verbal communication, it also an avenue for developing the motor skills of students. Hope [21] expressed that creating, developing, and communicating is the reason for drawing. While, Brooks [9] submitted that drawing helps beginners' to keep in mind and recall their lost recollections of images. In essence, Dee [13] reaffirmed that drawing is a bridge between the inner world of imagination, logic and the outer world of expression of ideas. Drawing has an artistic connotation, the visual difficulty solution for all designers, the simplest means of visualisation and a prominent individual activity [48].

\section{Uses of drawing}

Review of empirical studies on the usefulness of drawing revealed among others. For example, Lewis and Greene [29] stressed that drawing emphasises construction of lines as foundation for meaningful arrangement of objects drawing are laid in visual arts. Furthermore, the significance of drawing is seen as a process that allows learners to symbolize and visualised what they feel, see and know [30]. The study of Bartel [3] maintained that there is a balance of emotional satisfaction in learners, when they draw with diverse drawing media which includes charcoal. Author emphasised that drawing helps learners to value symbols, signs and representations. Also, Anning and Ring [5] accentuated the value of drawing as a means of communication and activities for mental growth. Bartel [3] opined that learners' ability to draw perfectly depends on the teacher methods of instruction and the teachers' interest. Anning and Ring [5] further expressed that problem of infant drawing that instructors often misunderstand and misinterpret their drawings, while they mislead the learners instead of mark-making which leads to writing and objects drawing to mere expression. Galbally [4] opined that drawing with different drawing media helps children to develop their dexterity for future legible handwriting skills. In this sense, drawing is regarded as an important agility in the school context because in develop the learners 
psychomotor, it serves as precursor to good writing skills [27].

Charcoal, assume to be the oldest form of drawing media, made by simply burning wooden branches and stick. It is called vine charcoal, this also available in a mechanically structures pattern. The vine charcoal is of three likenesses: soft, medium and hard. The soft charcoals provide a smoother feel to a drawing, artist doesn't have to apply forces and much pressure to get a solid black mark. Hard charcoal proffers more power but generally doesn't give much darkest tones. Compressed charcoals provide deeper blacks colour than vine charcoal, but are of more difficult to handle once they are applied to paper [42].

\section{Charcoal and Drawing}

On reviewed of charcoal and drawing, Salgado [42] submitted that charcoal softness characterised it as an acceptable, best ideal and powerful drawing media for tonal graduation. It is also very easy drawing medium and always easily to erase thereby gives quick impression to work with. Krauss [28] explained that charcoal is the most known oldest medium of drawing from charred sticks commonly used with the early cave dwellers purposely for both drawing and paintings. It is a medium that trace the outline of sketches and transforming the images and cartoons clearly on the mural. It is used for quick sketches and also for working out draft ideal. The softness attribute of charcoal favoured draftsman with the emphasis on the mass and movement of strokes rather than on linear meticulousness [26].
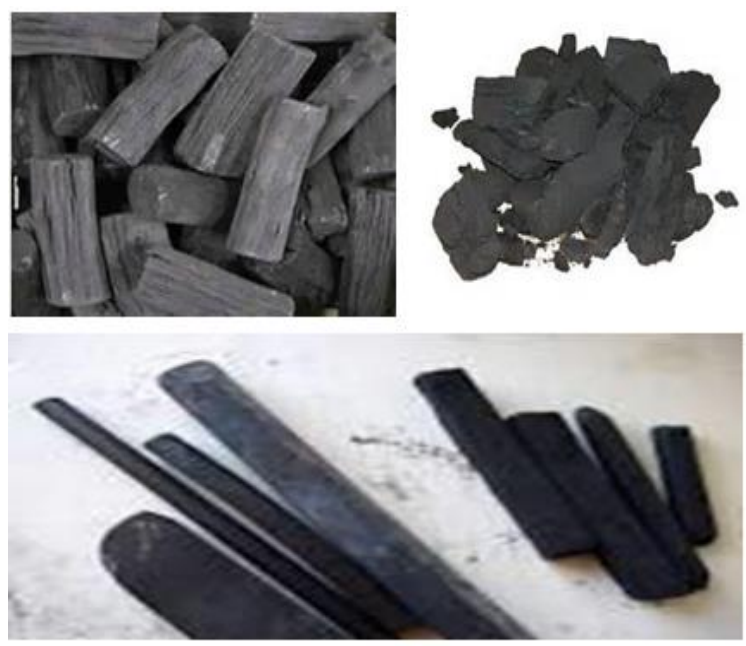

Figure 1. Charcoal Tablets

In another development of rendering charcoal drawing permanent on any medium of use, Arthistory [7] suggested that charcoal drawings can be rendered permanently by application of some transparent substance of gum, resin and fixative.
The usefulness of charcoal is not limited to drawing alone, study have proved the usefulness for syn gas production of automobile fuel. This is a spring of carbon in element reactions that may be triggered to increase its effectiveness as a sieve, utilised for a variety of health-related treatments and application for human use.

\section{Gender and charcoal drawing}

Studies on gender and charcoal drawing revealed that gender is of important in drawing because each exhibited their drawing along their pal [51]. The study of Golomb [17] expressed that (p. 20) gender are peculiar to each group comparing the product works of male and female of all ages in drawing. Papadakis-Michaelides [37] revealed that feminist studies have resulted in a large body of psycho sociological research comparing gender and sex in charcoal drawing. The sexist attitudes existed in instruction have contributed to changing attitudes in education.

In another development Salkind and Salkind [43] argued that behaviour in the drawing based on gender, the analyses of freehand drawings of boys and girls using different media especially charcoal revealed that there are certain similarities peculiar to the boys in terms of drawing that tend to focus on object and competition related to themes, while girls drawings deals with people and human relationships. Also, the characteristics of girls' charcoal drawings are of meticulous illustration of people, plants, animals and family scenes, while boys' drawings are more of scenery, actions, suspense, danger, weapons, rescue operations [56].

\section{Charcoal Drawing Packages}

The Charcoal drawing packages was developed from drawings based on charcoal as medium on white cardboard of half imperial, it is meant purposely to convey and disseminate information to students on stated goals. It can be said to be teaching and learning method as well as a process, which was based on a systematic approach of instructional development model put forward by Dick and Carey in the year 2005 [14]. The package was based on National University Commission accredited fine art course code FNA 201 titled General Drawing. The package contained of topics which were subdivided into six lessons, the meaning and types of drawings and shading technique. The content of the topics was prepared by the researchers with relevant materials from the Internet, textbooks and contributions from lecturers.

Ladoke Akintola, the name of renowned politician and a Premier of old Western State in Nigeria, was given to Oyo State University of Technology, Ogbomoso. Nigeria. The Institution is 
owned by both Oyo and Osun State respectively. The university started with six faculties, environmental sciences is one and department of fine and applied art is one of the departments in this faculty. The department of fine and applied art has been running courses in drawing and a course in general drawing for every new intake students of the institution. The course is a prerequisite for awarding the bachelor of technology degree. This department also runs Masters' degree programme in drawing.

The Theoretical framework is based on the sociocultural theories of development. The socio-cultural context stressed the importance of child learning, as being a crucial aspect of development and growth. Thus, learning in and through the arts is an action that is methodically knotted with social, academic and cognitive development [31]. The theory was proposed by Vygotsky in the year 1986 [54]; he further described learning as part of social events and understanding that occurred as a child plays with objects. Camp and Oesterreich [11] recommend that learner-centred, that is learning methods such as inquiry and constructivism in engaging the learners in inquiry learning in the classroom. On the other hand, Cole [12] suggested that group activities that pair learners to complement each other in learning new concepts. Children's ideology is perceived within their environment by their own culture; therefore, learners become intellectual when they are guided by the involvement of adults [40]. Similarly, Thompson [50] noted that the learning experience, artistic abilities and aesthetic values are products of socially mediated processes and the kinds of educational opportunities and limitations of the surrounding context. Therefore, Vygotsky argued that the child is seen as a social co-construct of meaning who plays a significant role in the world and his immediate environment [53]. He believed that the socio-cultural theory provides prospect to better understand learning process and the factors such as adults, peers, and the environment that influence that process.

\section{Statement of the problem}

The world is not static. The Technological innovations are being employed in delivery of instructional content to students. Studies have shown that technological devices like Computer Assisted Instructional Packages, Paintings Series Packages, Info graphic packages could bring about improvement in students' achievement, speeds up learning rate, enhances better retention, and encourages the development of better attitude [12]. However, the epileptic power supply for the use of these technologies especially in rural area has been a contributing problem.

Charcoal a medium of drawing has a long history of existence and usage especially with the early man in the cave for both drawings and painting. Negligence on the part of the users has rendered the uses of charcoal for drawing useless because of its scarcity and method of preservation. Drawing is crucial in Arts. It is believed to be the genesis, source, and foundation on which all Fine and Applied Arts courses are built. Undergraduate students of Fine and Applied Arts do perform below expectation in drawings courses, especially in areas of proportion, tone application, depth and medium used for their expressions.

Charcoal can be useful in teaching and instruction. However, limited studies are available to proof this. It is in the light of this, that, this study investigated the effectiveness of charcoal drawing packages on academic achievement of fine applied arts students of Nigeria University.

\subsection{Purpose of the Study}

The purpose of the study is to investigate the effectiveness of charcoal drawing packages on academic achievement of fine applied arts students of Nigeria University. Specifically, the study investigated the performances of undergraduate students that are exposed to charcoal drawing as medium of instruction.

\subsection{Research Questions}

The research answered the following questions:

- What is the difference in the performance of undergraduate students exposed to Charcoal Drawing Packages (CDP) as medium of instruction?

- What is the difference in the performance of male and female undergraduate students exposed to Charcoal Drawing Packages (CDP) as medium of instruction?

\subsection{Research Hypotheses}

The research hypotheses were tested at 0.05 level of significance:

- $\mathrm{HO}^{1}$ : There is no significant difference between the performances of undergraduates' students exposed to Charcoal Drawing Packages (CDP) as medium of instruction and those who were not.

- $\mathrm{HO}^{2}$ : There is no significant difference between the performances of undergraduates' male and female students exposed to Charcoal Drawing Packages (CDP) as medium of instruction. 


\section{Methodology}

The study adopted a quasi-experimental design pre-test and post-test group design.

\subsection{Sample and Sampling Technique}

The targeted population of this study was the undergraduate students of an approved university by the university commission for the past five years. Fine arts course as an accredited course in the university with availability of human and non-human recourses. Therefore, department of Fine and Applied Arts, faculty of environmental science, Ladoke Akintola University of Technology. Ogbomoso, Nigeria was chosen for the study. The sample for the study was drawn purposively from year two (200 level) Fine and Applied Arts undergraduate students. Sixty students were sampled, thirty-two boys and twenty-eight girls.

\subsection{Research instrument}

The major instrument used in generating data for this study was the Charcoal Drawings Packages and Test Instrument in Fine and Applied Arts (TIFAA). The charcoal Drawings Packages was validated by four lecturers of fine and applied arts from two selected undergraduate students of universities in Nigeria. Similarly, field trial validation of the treatment was carried out on 20 undergraduate students from a university which is part of the population but used for real experiment. Suggestions and comments from the experts and students were used in producing the final copy of the course material.

The test instrument is made up two sections. Section A is for students Bio-data such as: Name of institution, Department, Level, and Gender. Section $\mathrm{B}$ focused on the questions for eliciting responses from students. The items in the test (TIFAA) were taken from the validated Joint Admission Matriculation Board questions, which was made up of fifty (100) multiple choice objective items. There are five (5) options lettered (A-E) each item, out of which only "one" was correct. Students were instructed to select only one option as answer for each item. All the options were plausible answers to the item to measure specific learning outcomes related to the concept of the study. For the effect of test retest effect on the students, the questions were reordered and administered in a different arbitrary order as post-test. The scoring of the test, ' 1 ' mark for each correct answer and ' 0 ' for each wrong answer. The level of the significance adopted for the analysis was $\mathrm{P} \leq 0.05$. This level of significance formed the basis for accepting or rejecting the hypothesis.

\subsection{Procedure for Data Collection}

The researcher taught the content by exposing the students to thorough teaching on the topics with the Charcoal Drawing Packages (CDP) as medium of instruction. The teaching and instruction were on scanned pictures and topics of instruction compressed on compact disk, project through multimedia project to the students and later, practical drawings, demonstrations and explanations lasted for Six weeks. After which the test was administered on the group.

\subsection{Analysis of Findings}

Hypothesis 1: There is no significant difference between the performances of students exposed to Charcoal Drawing Packages as medium of instruction.

To test this hypothesis, the t-test statistics was used to compare the means scores of undergraduates students exposed to Charcoal Drawing Packages. The t-test statistics comparing the post-test means scores of students exposed to Charcoal Drawing Packages and those of conversional the result is provided below.

Table 1. Students Exposed to Charcoal Drawing Packages

\begin{tabular}{lllllll}
\hline GROUP & No & X & SD & df & F & Sig. \\
\hline Conventional & 30 & 69.43 & 6.76 & & & \\
Experimental & 30 & 69.70 & 7.70 & & & \\
\hline
\end{tabular}

The Table 1 shows that the calculated $F$ value of 092 is significant because the significant value of .76 is greater than 0.05 alpha level. The result implies that there is no significant difference in mean scores of the students. Therefore, the null hypothesis is accepted.

Hypothesis 2: There is no significant difference between the performance of male and female students exposed to Charcoal Drawing Packages as medium of instruction.

To test this hypothesis, the t-test statistics was used to compare the means scores of male and female undergraduates students exposed to Charcoal Drawing Packages.

The Means Scores of Male and Female Undergraduates Students Exposed to Charcoal Drawing Packages 
Table 2. Undergraduates Students Exposed to Charcoal Drawing Packages

\begin{tabular}{lcccccc}
\hline Gender & No & X & SD & df & F & Sig. \\
\hline Male & 28 & 73.79 & 5.60 & & & \\
& & & & 58 & 0.54 & .871 \\
Female & 32 & 66.72 & 6.52 & & & \\
\hline
\end{tabular}

The Table 2 shows that the calculated $F$ value of 0.54 is significant because the significant value of .871 is greater than 0.05 alpha level. This shows that there is no significant difference between the posttest means scores of male and female students. Male students' scores did not differ significantly from their female counterparts when both were taught using Charcoal Drawing Packages. Therefore, hypothesis two was not rejected.

\section{Discussion of Findings}

The first result on the analyses indicated there is no significant difference in the performances of students exposed to Charcoal Drawing Packages as medium of instruction. The results of the second hypothesis indicated no significant difference in the performance of male and female students taught using charcoal drawing packages.

In other words, Charcoal Drawing Packages can be related to Computer-supported Jigsaw ii Cooperative Learning where the performance of male and female students in the Jigsaw II group differ from the earlier findings of Olson [35] who reported that females performed better than males students when taught mathematics using cooperative learning. Also, the findings of Fakomogbon et al. [16] who confirmed that computer Assisted Instructional Package on mathematics shows that females performed better than males. The finding also disagreed with that of Anulobi [6] who study on Fine Arts with Video Compact Disc Instructional Package (VCDIP), where he reported that gender did not have any impact because both the boys and girls performed the same way.

\section{Recommendations}

Based on the major findings of this study, the following recommendations are proffered. Lecturers should expose the fine and applied arts students to charcoal drawings so as to improve students' performance in fine and applied arts. In addition, government, educational agencies and other education stakeholders should organize workshops on the use of charcoal drawing packages to enhance better performance of undergraduate students.

The curriculum of teacher education programme in Nigerian tertiary institutions should be improved upon in such a way that they would be teachers will be exposed to different teaching methods. This will thereby produce teachers who can apply innovative teaching approaches including Charcoal Drawing Packages, which will eventually promote effective teaching and learning.

\section{Conclusion}

It can be concluded that the charcoal drawing package as medium of instruction is good in teaching drawing to the undergraduates' students. Therefore, charcoal should not be left out in the uses of drawing media in the university and that Charcoal Drawings Packages should be integrated in teaching Fine and Applied Arts because it improves academic performance of students and enhance effective instructional delivery.

\section{References}

[1] Adams, E. (2006). Drawing insights. London: The Campaign for Drawing.

[2] Annetta, L., Mangrum, J., Holmes, S., Collazo, K. and Cheng, M., (2009). Bridging realty to virtual reality: Investigating gender effect and students' engagement on learning through video game play in an elementary school classroom. International Journal of Science Education, 31(8), 1091-1113.

[3] Bartel, M., (2010). How to teach drawing to children. Retrieved May 5, 2012 from http://www.goshen.edu/art/ed/draw.html

[4] Galbally, A., (2004). Patron of the arts at the Antipodes. La Trobe Journal, 73 (10), 734-748.

[5] Anning, A. and Ring, K. (2004). Making Sense of Children's Drawings. Maidenhead: Open University Press.

[6] Anulobi, J. C., (2009). Effect of the Use of Video Compact Disc Instructional Package (VCDIP) on Academic Performance of Junior Secondary School Fine Arts Students in Owerri. Journal of Educational Technology and Instruction, (JETI), 1(1), 31-36.

[7] Arthistory, N. (2013). Charcoal: the History and Development of a Medium. Retrieved August 15, 2012, www.arthistory.netartmedums/charcoal/charco al.html.

[8] Bae, J. (2004). Learning to teach visual arts in an early childhood classroom: The teacher's role as a guide. Early Childhood Education Journal, 31; 247254.

[9] Brooks, M., (2003). Drawing to learn. http://www.na eyc.org (Access Date: 6 April, 2012). 
[10] Bowman, B., Donovan, M., and Burns, M., (eds). (2001). Eager to learn: Educating our preschoolers. Washington DC: National Academy Press.

[11] Camp, E. M., and Oesterreich, A., (2010). Uncommon teaching in commonsense times: A case study of a critical multicultural educator and the academic success of diverse student populations'. Multicultural Education, 22. Retrieved June 25, 2012 from www.thefreelibrary.com.

[12] Cole, S., (2009). Accommodations and instructional strategies that can help students. Vermont: Department of Education. www.http//state.vt.us (Access Date: October 15, 2012).

[13] Dee, C., (2008). Plus and Minus: Critical Drawing for Landscape Design, in: Treib, 60-72.

[14] Dick W. and Carey, J.O., (2005). The systematic design instruction (6th ed.) New York NJ: Harper Collins Publishers

[15] Elom, N. E., (2014). Effective Teaching and Learning in Technical Colleges: Challenges of Technical Drawing. Journal of Educational Policy and Entrepreneurial Research (JEPER), 1, (1),76-86.

[16] Fakomogbon, M. A. Adetayo A. O. Oyebode, M. S. and Enuwa M. R., (2014). Effect of Computer Assisted Instructional Package on the performance of students in Mathematics in Ilorin metropolis. European Scientific Journal Edition, 10(25), 25-40.

[17] Golomb, C., (2004). The child's creation of a pictorial world. Mahwah, NJ: Lawrence Earlbaum Associates.

[18] Hall, E., (2009). Mixed messages: The role and value of drawing in early education. International Journal of Early Years Education, 17(3), 179-190.

[19] Hawkins, B., (2002). Children's drawing, selfexpression, identity and imagination. Journal of Art and Design Education, 21(3), 209-219.

[20] Hecker, J, B, and Kentridge W. (2010). Trace, Prints from The Museum of Modern Art, The Museum of Modern Art, New York.

[21] Hope, G. (2008). Thinking and learning through drawing. London:

[22] Hopperstad, M. H., (2010). Studying meaning in children's drawings. Journal of Early Childhood Literacy, 10(4), 430-452.
[23] Jarvis, M. (2004). The importance of painting in pedagogic practice. Journal of Art and Design Education, 23; 316-325.

[24] John P., (2012). Activated Charcoal Overview. A Medicine Health, Web MD, Inc. Retrived13 October, 2012 from http://www.actcharcol.org

[25] Keefe, D. F., Zeleznik, R. C., and Laidlaw D. H., (2007). Drawing on air: Input techniques for controlled 3D line illustration. IEEE Transactions on Visualization and Computer Graphics, 13(5), 10671080.

[26] Kentridge, W., and Law-Viljoen B., Kentridge, W., (2010). Thirty Etchings. David Krut Publishing, Johannesburg.

[27] Kesicioglu, S. G., and Deniz, U., (2014). Investigation of Pre - School Children's Perception of Teacher in Their Drawings. Creative Education. 5, 606-613

[28] Krauss, R. E., (2000). The rock: Drawings for Projection. London. William Kentridge Publishers.

[29] Lewis, D., and Greene, J., (1983). Young child's drawings - Their hidden meaning. Hutchinson and Co. (Publishers) Ltd

[30] López-Sáez, M., Morales, J. F. and Lisbona, A., (2008). Evolution of gender stereotypes in Spain: traits and roles. The Spanish Journal of Psychology, 11, 609-617.

[31] Mason, C., and Steedly, K., (2006). Rubrics and an arts integration community of practice. Teaching Exceptional Children, 89; 36-43.

[32] Mamza, P. M., (2010 May). Vocational Technical Education and Rebranding. Nigeria. Paper presented at the 4th National Conference of the School of Vocational Education. Federal College of Education Kontagora.

[33] Okanlawon, A. K., (2017). Yoruba cultural signs and symbols, a synthetics of painting expression. Inaugural Lecture Series 12. The polytechnic Ibadan, Nigeria.

[34] Okorie, J. U., (2001). Introduction to Vocational Education. Unpublished Manuscripts. Department of Vocational Teacher Education. University of Nigeria.

[35] Olson, V. E., (2002). Gender differences and the effects of cooperative learning in college level mathematics. Unpublished Ph.D thesis, Curtin University of Technology, Perth, Western Australia. 
[36] Pérez-Gómez and Pelletier., (2000). Architectural representation and the perspective hinge, Cambridge, London, MIT Press.

[37] Papadakis-Michaelides, E., (1989). Development of Children's Drawings in Relation to Gender and Culture. (Unpublished Ph.D. Thesis). University of Birmingham.

[38] Rabkin, N. and Hedberg, E. C., (2011). Arts education in America: What the declines means for arts participation. University of Chicago: National Endowment for the Arts. http://www.arts. (Access Date: 6 May, 2012).

[39] Rubin, J., (1984). Child art therapy: Understanding and helping children grow through art (2nd Ed.). New York: Van Nostrand Reinhold.

[40] Rogoff, I., (1998). Studying Visual Culture. In Mirzoeff N. (Eds). Visual Culture Reader. London: Routledge, 14-26.

[41] Saibu, M. O., (2013). Continental Junior Secondary Cultural And Creative Arts, Book One. Continental Groups of Publishers, Ring Road Ibadan.

[42] Salgado. A., (2014). Charcoal Drawing, Oil painting indifference. Retrieved May 6, 2016 from www.andrewsalgado.com/info/statement.

[43] Salkind, L., and Salkind, N. J., (1997). Gender and age differences in preference for works of art. Studies in Art Education, 39, 246-256.

[44] Saylor M., (2011). Types of Drawing Media. http://www.saylor.org (Access Date: 5 May, 2012).

[45] Sobel, D., (1998). Mapmaking with children: Sense of place education for the elementary years. Portsmouth, NH: Heinemann.

[46] Szántó, C., (2010). A graphical analysis of versailles garden promenades, Journal of Landscape Architecture (Spring), 52-59.

[47] Taylor, J. B., Branscombe, A. N., Burcham, G. J., and Land, L., (2011). Beyond early literacy. New York and London: Routledge.

[48] Toorn, M. van den., and Have, R., (eds.), (2010). Visualisation in urban design and landscape architecture, Delft, Faculty of Architecture.

[49] Toorn, M. van den., (2009). Hand drawing as a means of acquiring visual knowledge, in: Gómez Chova et al., 677-684
[50] Thompson C. M., (2005). The Ket Aesthetic: Visual Culture in Childhood. International Journal of Art Education, 3 (1), 68-88.

[51] Tuman, D., (2001). Defining differences: An historical overview of the research regarding the difference between the drawings of boys and girls. The Journal of Gender Issues in Art Education, 1; 17-30.

[52] Usman, A., Odewumi, O., Obotuke, E., Apolola, O., and Ogunyinka, C. O., (2014). Cultural and Creative Arts Book One for Junior Secondary Schools. Spectrum Books Limited, Ring road Ibadan.

[53] Vygotsky, L. V., (1978). Mind in society: The development of higher psychological processes. Cambridge, MA: Harvard University Press.

[54] Vygotsky, L. S., (1986). Thought and Language. Cambridge, Massachusetts: MIT Press.

[55] Vygotsky, L. S., (1999). The collected works of LS. Vygotsky. Scientific Legacy (M.J.) 6.

[56] Wilson, M., and Wilson, B. (1982). Teaching children to draw: A guide for parents and teachers. Upper Saddle River, NJ: Prentice Hall. 